Biochimica et Biophysica Acta, 592 (1980) 546-558

(C) Elsevier/North-Holland Biomedical Press

BBA 47913

\title{
EFFECTS OF BULK pH AND OF MONOVALENT AND DIVALENT CATIONS ON CHLOROPHYLL a FLUORESCENCE AND ELECTRON TRANSPORT IN PEA THYLAKOIDS
}

\author{
DANIEL WONG ${ }^{a, *}$, GOVINDJEE $a, b, * *$ and HENRI MERKELO ${ }^{c}$ \\ Departments of a Physiology and Biophysics, ${ }^{\mathrm{b}}$ Botany, and $\mathbf{c}$ Electrical Engineering, \\ University of Illinois, Urbana, IL 61801 (U.S.A.)
}

(Received December 11th, 1979)

(Revised manuscript received April 29th, 1980)

Key words: pH effect; Cation effect; Chlorophyll a fluorescence; Electron transport; Thylakoid; (Pea)

\section{Summary}

Millimolar concentrations of monovalent cations enhance and divalent cations impede the redistribution (spill-over) of electronic excitation energy from Photosystem (PS) II to PS I in cation-depleted (sucrose-washed) thylakoids; this concept is based on chlorophyll $a$ fluorescence and electron transport measurements over a narrow $\mathrm{pH}$ range around 7 . We have tested the above concept in pea thylakoids over the $\mathrm{pH}$ range 5 to 9 by parallel measurements of various chlorophyll $a$ fluorescence parameters (spectra, transients, and lifetimes at $77 \mathrm{~K}$ and $293 \mathrm{~K}$, and polarization at $293 \mathrm{~K}$ ) and of the rates of partial reactions of PSI and II.

Our results provide the following information.

(1) $\mathrm{Mg}^{2+}$ enhancement of fluorescence is maximum between 680 and 690 $\mathrm{nm}$ and minimum between 710 and $720 \mathrm{~nm}$.

(2) The optimum conditions for the observation of the $\mathrm{Mg}^{2+}$-induced enhancement of fluorescence are: wavelength of emission, $685 \mathrm{~nm}$; concentration of $\mathrm{Mg}^{2+}, 10 \mathrm{mM}$, and $\mathrm{pH}, \sim 7.5$.

(3) $\mathrm{Mg}^{2+}$ decreases the efficiency of excitation redistribution from PS II to PS I over the $\mathrm{pH}$ range 6 to 9 .

\footnotetext{
* Present address: Miles Laboratories, Inc., P.O. Box 70, Elkhart, IN 46515, U.S.A.

* To whom correspondence should be addressed: Department of Botany, 289 Morrill Hall, University of Wlinois, Urbana, IL 61801, U.S.A.

Abbreviations: DAD, diaminodurene; DBMIB, dibromothymoquinone; DCMU, 3-(3,4 dichlorophenyl)1,1-dimethylurea or, diuron; DCIP (or DCPIP), dichlorophenol indophenol; PS I, Photosystem I; PS II, Photosystem II; Chl, chlorophyll.
} 
(4) The antagonistic effects between $\mathrm{Na}^{+}$and $\mathrm{Mg}^{2+}$ hold simultaneously for both the fluorescence intensity and lifetime, at physiological temperatures, only within the $\mathrm{pH}$ range 6 to 8 .

(5) $\mathrm{Mg}^{2+}$ enhances the light-limited electron transport rate through PS II in the $\mathrm{pH}$ range 5.4 to 8.2 and decreases that through PS I at pH 7.1 and 8.2. The $\%$ increase in PS II is, however, about twice the \% decrease in PS I.

\section{Introduction}

Monovalent and divalent cations play a crucial role in the regulation of net electronic excitation energy distribution between the two photosystems of green plant photosynthesis $[1,2]$. We present here the effects of varying the bulk $\mathrm{H}^{+}$concentration in the suspension medium on this excitation energy regulation in pea thylakoids.

The purpose of the present investigation was three fold.

First, define the $\mathrm{pH}$ range over which the existing findings on cation-induced fluorescence changes hold, since most studies have been made over the narrow $\mathrm{pH}$ range of 7 to 8 . This is particularly important since the $\mathrm{pH}$ of the intrathylakoid space (loculus) show large variations in normal operation [1].

Second, re-examine the antagonistic effects of $\mathrm{Mg}^{2+}$ on electron transport in photosystem (PS) I and PS II as a function of $\mathrm{pH}$ because the inhibiting effect [3] of $\mathrm{Mg}^{2+}$ at $\mathrm{pH}>7.5$ on PS I electron transport (measured as the rate of $\mathrm{NADP}^{+}$reduction) turns into an enhancing effect at $\mathrm{pH}<7.5$ [4].

Third, provide a comprehensive study, through parallel measurements, of the $\mathrm{pH}$ dependence of the cation effects on various aspects of chlorophyll $a$ fluorescence and electron transport in the two photosystems, in order to clarify the regulatory phenomenon of excitation energy distribution. Since Barber et al. [5] have reported that the cation effects on chlorophyll $a$ fluorescence correlate with the membrane surface charge density, and that the electrophoretic mobility of the thylakoids is constant in the $\mathrm{pH}$ range 6 to 10, it was important to know whether or not the cation effects are also $\mathrm{pH}$ insensitive.

\section{Materials and Methods}

Thylakoids were prepared as described in Ref.6. The final suspension medium contained $100 \mathrm{mM}$ sucrose and $2 \mathrm{mM}$ Tris adjusted to an appropriate $\mathrm{pH}$ with $\mathrm{HCl}$ or $\mathrm{HNO}_{3}$. Since the concentrated stock thylakoid membranes, suspended in $100 \mathrm{mM}$ unbuffered sucrose, showed slightly acidic $\mathrm{pH}$, the final measured $\mathrm{pH}$ of each sample was $0.4-0.8$ unit lower than the $\mathrm{pH}$ of the dilution medium. Other sample details were as given in the legends of figures and tables. Diuron, when used, was added prior to cations, and, the measurements were made at least $10 \mathrm{~min}$ after incubation in the final suspension.

Chlorophyll $a$ fluorescence spectra and transients were measured with an instrument described elsewhere [7,8]. For measurements at $77 \mathrm{~K}, 0.5-\mathrm{ml}$ aliquots of thylakoid suspension were adsorbed onto two layers of cheese-cloth $(0.3 \mathrm{~mm}$ thickness) and frozen in liquid nitrogen. All fluorescence spectra were corrected for monochromator transmission characteristics and photocathode 
(S20) sensitivity. The degree of polarization of fluorescence was measured as described elsewhere $[9,10]$. Fluorescence lifetimes $(\tau)$ were measured by the phaseshift method using a mode-locked He-Ne laser $(\lambda=632.8 \mathrm{~nm}$; modulation frequency $=75 \mathrm{MHz}$ ) [11]. With the exception of the fluorescence polarization $(P)$ which utilized right angle geometry, all other fluorescence parameters were measured from the same surface as the incident irradiation.

Electron transport rates in the partial reactions were measured either optically, as the rate of bleaching of $\mathrm{DCIPH}_{2}$ at $597 \mathrm{~nm}$, or, as the rate of oxygen evolution or uptake, by a Clark-type electrode in a water jacketed chamber and an oxygen monitor (Yellow Springs Instrument, Model 53). The extinction coefficients of DCIP at different $\mathrm{pH}$ values were determined as in Ref. 12. Chlorophyll concentrations were determined by the method described in Ref. 13. The temperature was $23 \pm 1^{\circ} \mathrm{C}$.

\section{Results}

\section{Cation effects on chlorophyll a fluorescence}

Cation concentration curves for maximum yield of fluorescence in diurontreated thylakoids

The optimum concentrations of cations to be used were determined from cation concentration dependence of the maximum steady-state yield (fluorescence intensity/absorbed intensity) of fluorescence, $F_{\mathrm{m}}$ (corresponding to the $\mathrm{P}$ level) at $685 \mathrm{~nm}$ in salt-depleted thylakoids ([Chl], $5 \mu \mathrm{g} \cdot \mathrm{ml}^{-1}$ ) treated with $3.3 \mu \mathrm{M}$ diuron at $\mathrm{pH} 6.2,7.1$, and 8.6 (Fig. 1). With $F_{\mathrm{m}}$ for the saltdepleted sample in each case normalized to 1.0, the following is noted:

(1) There are two phases (Fig. $1 \mathrm{~A})$ in the cation $\left(\mathrm{Na}^{+}\right.$and $\left.\mathrm{Mg}^{2+}\right)$ concentra-
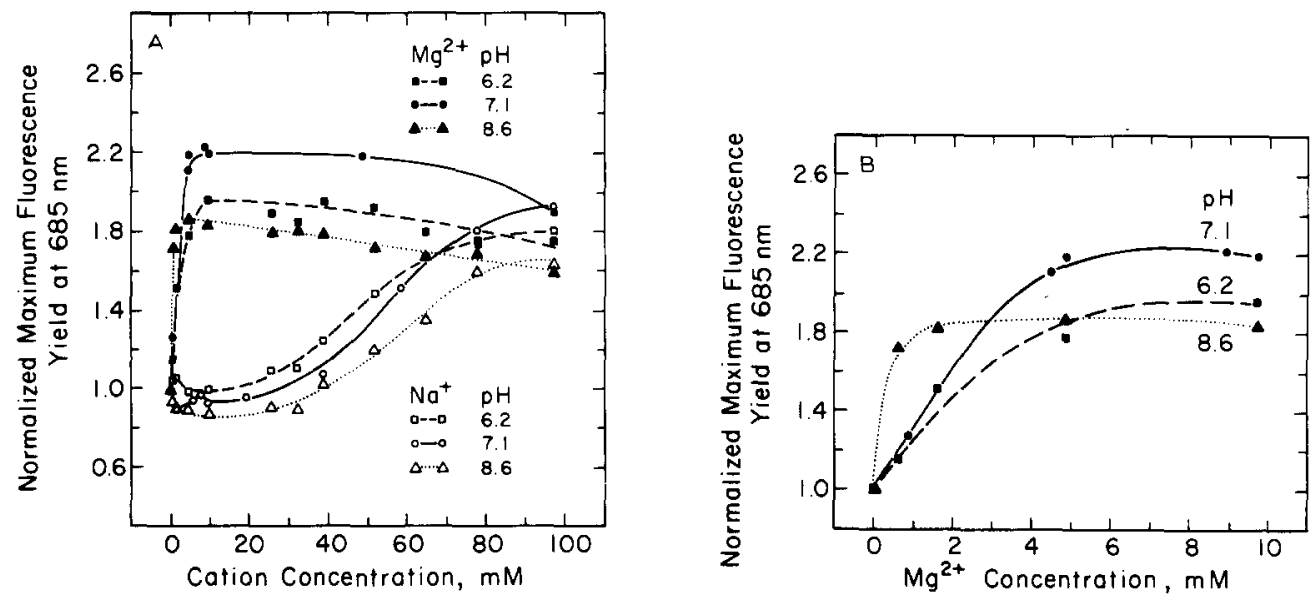

Fig. 1. The maximum relative yield of fluorescence at $685 \mathrm{~nm}$ as function of the cation concentrations, for three $\mathrm{pH}$ values. (A) The effect of $\mathrm{Na}^{+}$or $\mathrm{Mg}^{2+}$ over the concentration range $0-100 \mathrm{mM}$. (B) The fluorescence enhancement with increasing $\mathrm{Mg}^{2+}$ concentration between 0 and $10 \mathrm{mM}$ replotted to demonstrate the $\mathrm{pH}$ dependent shift in $\left[\mathrm{Mg}^{2+}\right]$ for half-maximum enhancement. Thylakoids suspended in 100 $\mathrm{mM}$ sucrose $+2 \mathrm{mM}$ Tris-HCl (appropriate $\mathrm{pH}$ ); $[\mathrm{Chl}]=5 \mu \mathrm{g} / \mathrm{ml} ;[\mathrm{DCMU}]=3.3 \mu \mathrm{M}$; temperature $=23^{\circ} \mathrm{C}$. Excitation was at $636 \mathrm{~nm}$ (half-bandwidth, $8 \mathrm{~nm}$ ). 
tion curves for $F_{\mathrm{m}}$. The maximum fluorescence, $F_{\mathrm{m}}$, increases sharply as $\left[\mathrm{Mg}^{2+}\right]$ is increased frrom 0 to $5 \mathrm{mM}$, attaining a maximum at $6-8 \mathrm{mM}$, and then declines slightly from 10 to $100 \mathrm{mM}$. In the case of $\mathrm{Na}^{+}$, however, $F_{\mathrm{m}}$ shows an ' $S$ '-shaped dependence on its concentration; in the 20-40 mM range (depending on $\mathrm{pH}$ ), $F_{\mathrm{m}}$ decreases slightly, but, beyond $\sim 40 \mathrm{mM}$, it increases, saturating at $\sim 100 \mathrm{mM}$ (cf. Ref. 14). At $\sim 100 \mathrm{mM}$, both $\mathrm{Na}^{+}$and $\mathrm{Mg}^{2+}$ give the same $F_{\mathrm{m}}$.

(2) $F_{\mathrm{m}}$ in the presence of $10 \mathrm{mM} \mathrm{Mg}^{2+}$ is highest at $\mathrm{pH} 7.1$, followed by $\mathrm{pH}$ 6.2 , and then pH 8.6 (Fig. 1). $10 \mathrm{mM} \mathrm{Na}^{+}$, on the other hand, induces a greater decrease in $F_{\mathrm{m}}$ at $\mathrm{pH} 8.6$ than at $\mathrm{pH} 7.1$; at $\mathrm{pH} 6.2$, there is only a very slight change in $F_{\mathrm{m}}$ (Fig. $1 \mathrm{~A}$ ).

(3) The half-saturation concentration for the $\mathrm{Mg}^{2+}$-induced increase in $F_{\mathrm{m}}$ shifts to lower values with increasing $\mathrm{pH}$ (Fig. 1B).

\section{pH dependence of cation effects on chlorophyll a fluorescence at room temperature}

Emission spectra. The room temperature emission spectra of thylakoid suspensions at $\mathrm{pH} 5.3,6.3,7.8$ and 8.9 are similar to each other, although the relative enhancement by $10 \mathrm{mM} \mathrm{Mg}{ }^{2+}$ is different in each case. From 5.3 to $8.9 \mathrm{pH}$, the main emission peak is at $\sim 685 \mathrm{~nm}$ with a smaller band at $\sim 730$ $\mathrm{nm}$, as is known for chloroplasts at $\mathrm{pH}$ 7.0. The quotient of the emission intensity of a sample containing $10 \mathrm{mM} \mathrm{Mg}^{2+}$ and $10 \mathrm{mM} \mathrm{Na}^{+}$to that of a sample without $\mathrm{Mg}^{2+}$ but with $10 \mathrm{mM} \mathrm{Na}$, at various $\mathrm{pH}$ values, is strongly dependent upon emission wavelength (Fig. 2). At pH 6.3 or greater, this ratio shows a large $\mathrm{Mg}^{2+}$-induced enhancement between 670 and $690 \mathrm{~nm}$; this enhancement declines monotonically beyond $690 \mathrm{~nm}$ to a minimum at $710-$ $720 \mathrm{~nm}$, followed by a rise, and, perhaps, a final decline beyond $750 \mathrm{~nm}$. At $\mathrm{pH}$ 5.4, only a slight wavelength independent increase is observed.

Maximum steady-state yield. Figs. $1 \mathrm{~A}$ and 2 show that the ideal conditions for the study of cation effects on chlorophyll $a$ fluorescence in the $\mathrm{pH}$ range 6 to 9 are to measure the emission at $\sim 685 \mathrm{~nm}$ in the presence of $10 \mathrm{mM}$ cations. To determine the optimum $\mathrm{pH}$, the maximum steady-state fluorescence yield $\left(F_{\mathrm{m}}\right)$ of the thylakoids suspended in cation-free $\mathrm{Na}^{+}(10 \mathrm{mM})$, and $\mathrm{Na}^{+}(10 \mathrm{mM})+$ $\mathrm{Mg}^{2+}(10 \mathrm{mM})$ media in the presence of $3.3 \mu \mathrm{M}$ diuron was measured (Fig. 3). The profiles of $F_{\mathrm{m}}$ for the three conditions are different. In cation-depleted medium (open circles), $F_{\mathrm{m}}$ shows an increase from $\mathrm{pH} 5.0$ to a peak at $\mathrm{pH} 6.3$, then a decline to a relative minimum at $\mathrm{pH} 7.7$, and a slight rise thereon to $\mathrm{pH}$ 9 . With the addition of $10 \mathrm{mM} \mathrm{Na}{ }^{+}$(closed squares), $F_{\mathrm{m}}$ shows a broad maximum around $\mathrm{pH} \mathrm{5.7,} \mathrm{intersecting} \mathrm{the} \mathrm{previous} \mathrm{curve} \mathrm{at} \mathrm{pH} \sim 6.1$, so that $F_{\mathrm{m}}$ $\left(\mathrm{Na}^{+}\right)$is greater than $F_{\mathrm{m}}$ (cation-free) at low $\mathrm{pH}$ and smaller at high $\mathrm{pH}$. In the presence of $10 \mathrm{mM} \mathrm{Mg}{ }^{2+}$ (closed triangles), $F_{\mathrm{m}}$ peaks at $\mathrm{pH} 7.7$, with $F_{\mathrm{m}}(\mathrm{pH}$ $7.7)=2 F_{\mathrm{m}}(\mathrm{pH} 5) \simeq 1.5 F_{\mathrm{m}}\left(\mathrm{pH} \mathrm{8.8)}\right.$. Addition of $10 \mathrm{mM} \mathrm{Na}^{+}$to salt-depleted thylakoids gives a $\sim 20 \%$ increase in $F_{\mathrm{m}}$ at $\mathrm{pH} \sim 5.0$ but a $\sim 35 \%$ decrease at $\mathrm{pH} 8.8$, the transition over the $\mathrm{pH}$ range being almost linear. The enhancement in fluorescence yield upon the addition of $10 \mathrm{mM} \mathrm{Mg}^{2+}$ to a sample containing $10 \mathrm{mM} \mathrm{Na}{ }^{+}$rises dramatically from $\sim 10 \%$ at $\mathrm{pH} 5.0$ to $>300 \%$ at $\mathrm{pH} \mathrm{7.7}$, followed by a slight drop at $\mathrm{pH} 8.8$.

Transients. To estimate how much effect cations have on the constant $\left(F_{\mathrm{o}}\right)$ 

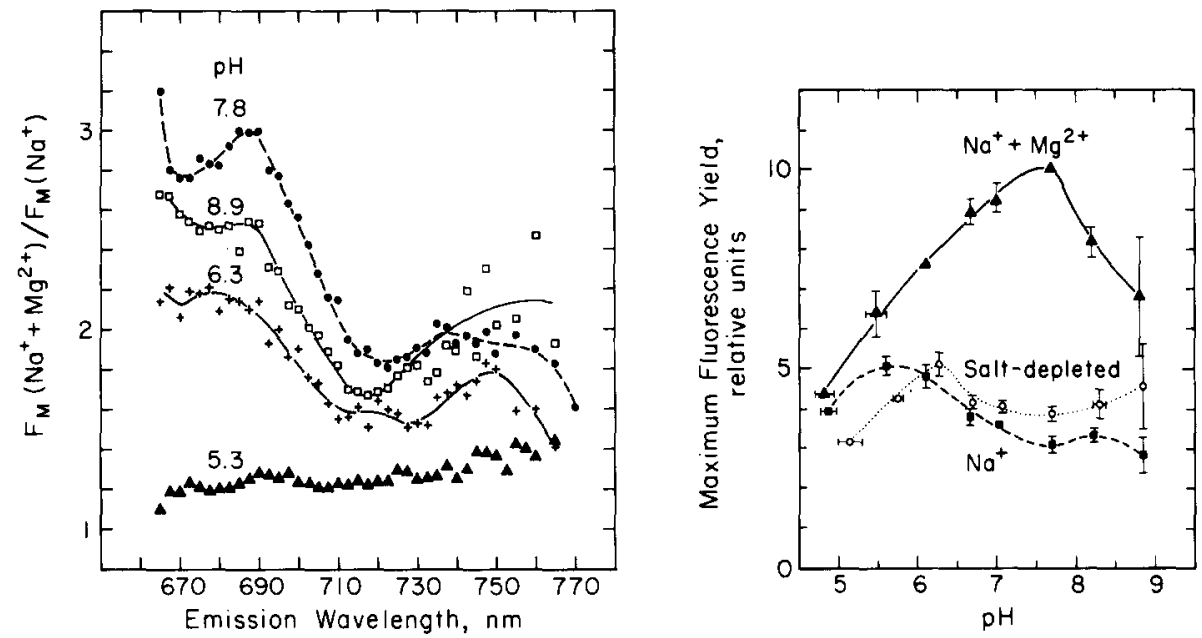

Fig. 2. The effect of $\mathrm{Mg}^{2+}$ on the fluorescence emission spectrum at $296 \mathrm{~K}$ : fluorescence intensity ratio between the $\mathrm{Na}^{+}+\mathrm{Mg}^{2+}$ and the $\mathrm{Na}^{+}$sample as function of emission wavelength, for four $\mathrm{pH}$ values. Excitation was at $636 \mathrm{~nm}$ (half-bandwidth, $8 \mathrm{~nm}$ ), and fluorescence was detected through a Schott RG 665 glass filter and a monochromator (band-pass, $6.6 \mathrm{~nm}$ ). All spectra were corrected for transmission characteristics of filter and monochromator, photomultiplier sensitivity, and background light. [Chl] $=5 \mu \mathrm{g} / \mathrm{ml}$; $\left[\mathrm{Na}^{+}\right]=\left[\mathrm{Mg}^{2+}\right] \simeq 10 \mathrm{mM} ;[\mathrm{DCMU}]=3.3 \mu \mathrm{M}$.

Fig. 3. $\mathrm{pH}$ dependence of the maximum relative fluorescence yield at $685 \mathrm{~nm}$ for the salt-depleted, $\mathrm{Na}^{+}$, and $\mathrm{Na}^{+}+\mathrm{Mg}^{2+}$ samples. Fluorescence excitation was at $636 \mathrm{~nm}$ (half-bandwidth, $8 \mathrm{~nm}$ ) and detection was through a grating monochromator set at $685 \mathrm{~nm}$ (band-pass, $6.6 \mathrm{~nm}$ ). Other details were as given in the legend of Fig. 1.

and variable $\left(F_{\mathrm{v}}=F_{\mathrm{m}}-F_{\mathrm{o}}\right)$ parts of fluorescence, transients were measured (Table I). In both the salt-depleted and the $\mathrm{Na}^{+}$samples, $F_{\mathrm{o}}$ at $\mathrm{pH} 7.8$, is lower than at $\mathrm{pH} 6.0$ and $\mathrm{pH} 8.9$. In the $\mathrm{Na}^{+}+\mathrm{Mg}^{2+}$ sample, $F_{\mathrm{o}}$ at the two lower $\mathrm{pH}$ values is about the same, but is lower at the highest pH. $F_{\mathrm{o}}$ decreases slightly upon $\mathrm{Na}^{+}$addition to salt-depleted thylakoids, for all $3 \mathrm{pH}$ values but it increases significantly $(\sim 60 \%)$ upon the addition of $\mathrm{Mg}^{2+}$ only at $\mathrm{pH} 7.8$ (cf. Ref. 15), no change being observed at $\mathrm{pH} 6.1$ and 8.9.

\section{TABLE I}

CATION EFFECTS ON THE INITIAL AND THE MAXIMUM RELATIVE FLUORESCENCE YIELD AT $23^{\circ} \mathrm{C}$ AT 3 DIFFERENT PH VALUES

Fluorescence was measured at $685 \mathrm{~nm}$ through a monochromator (band-pass, $6.6 \mathrm{~nm}$ ). Excitation was with broad-band blue light, white light passed through Corning CS 3-73+CS 4-96 filters. [Chl] $=5 \mu \mathrm{g} / \mathrm{ml}$.

\begin{tabular}{|c|c|c|c|c|c|c|c|c|c|}
\hline \multirow[t]{2}{*}{ Sample } & \multicolumn{3}{|c|}{ pH $6.1 \pm 0.2$} & \multicolumn{3}{|c|}{ pH $7.8 \pm 0.1$} & \multicolumn{3}{|c|}{ pH $8.9 \pm 0.1$} \\
\hline & Fo * & $F_{\mathrm{m}}$ & $\frac{F_{\mathrm{V}}}{F_{\mathrm{m}}}$ & $F_{\mathrm{o}}$ & $F_{\mathrm{m}}$ & $\frac{F_{\mathrm{v}}}{F_{\mathrm{m}}}$ & $F_{\mathrm{o}}$ & $F_{\mathrm{m}}$ & $\frac{F_{\mathrm{V}}}{F_{\mathrm{m}}}$ \\
\hline Salt-depleted & 10.0 & 20.7 & 0.52 & 5.7 & 12.7 & 0.55 & 7.1 & 17.0 & 0.58 \\
\hline $10 \mathrm{mM} \mathrm{NaCl}$ & 8.5 & 16.9 & 0.50 & 5.4 & 10.2 & 0.47 & 6.9 & 15.2 & 0.55 \\
\hline $10 \mathrm{mM} \mathrm{NaCl}+10 \mathrm{mM} \mathrm{MgCl}_{2}$ & 8.6 & 20.1 & 0.57 & 8.5 & 27.8 & 0.69 & 6.9 & 15.2 & 0.55 \\
\hline
\end{tabular}

* $F_{O}$, also called the o level or 'constant fluorescence' is the initial yield of fluorescence upon illumination of a sample; $F_{m}$, also called $P$ level fluorescence, the maximum yield of fluorescence attained during illumination, and the variable fluorescence $F_{\mathrm{v}}=F_{\mathrm{m}}-F_{\mathrm{o}}$. 
At $\mathrm{pH} 7.8$, the ratio of $F_{\mathrm{v}}$ to $F_{\mathrm{m}}$ (in Table I) shows cation-induced changes similar to those in Ref. 6 for the $\mu \mathrm{s}$ fluorescence transient induced by a single $10 \mathrm{~ns}$ flash: a decrease in the ratio with addition of $\mathrm{Na}^{+}$and an increase with a subsequent addition of $\mathrm{Mg}^{2+}$. However, these effects are either diminished or absent at higher and lower values of $\mathrm{pH}$.

Lifetimes. For both the salt-depleted and $\mathrm{Na}^{+}$samples, fluorescence lifetime of $F_{\mathrm{m}}$ at $686 \mathrm{~nm} \tau\left(F_{686, \mathrm{~m}}\right)$ shows a general decline with increasing pH (Fig. 4). In the $\mathrm{Na}^{+}+\mathrm{Mg}^{2+}$ sample, the $\mathrm{pH}$ profile of $\tau\left(F_{686, \mathrm{~m}}\right)$ shows a broad peak around $\mathrm{pH} 7.5$. The maximum relative fluorescence yields at $686 \mathrm{~nm}, F_{686, \mathrm{~m}}$, simultaneously measured with $\tau\left(F_{686, \mathrm{~m}}\right)$, show similar $\mathrm{pH}$ profiles. Also, the $\mathrm{pH}$ profiles of the $\tau\left(F_{686, \mathrm{~m}}\right)$ in Fig. 4 closely resemble those from steady-state fluorescence yield measurements in diuron treated thylakoids (Fig. 3), suggesting that the $\mathrm{pH}$ profiles of $\tau$ may be diruon insensitive.

Polarization. The degree of polarization of fluorescence $(P)$ at $686 \mathrm{~nm}$ was measured at $\mathrm{pH} 6.6$ and 9.0 (Table II). Results at $\mathrm{pH} 7.6$ were reported earlier [9]. Addition of $\mathrm{Na}^{+}$induces a greater increase in $P$ of $F_{686, \mathrm{~m}}$ at $\mathrm{pH} 6.6(\sim 11 \%)$ than at $\mathrm{pH} 9.0(4 \%)$. The $\mathrm{Mg}^{2+}$-induced decrease in $P$ is about the same ( $\sim 10-$ $13 \%$ ) at both $\mathrm{pH}$ values. These changes in $P$ are consistent with a $\mathrm{Na}^{+}$-induced decrease in energy migration in PS II and a $\mathrm{Mg}^{2+}$-induced increase in such migration, over the $\mathrm{pH}$ range 6.6 to 9.0 (cf. Ref. 9).

pH dependence of cation effects on chlorophyll a fluorescence at $77 \mathrm{~K}$

Lifetimes. The $\tau$ at the $P$-level at $77 \mathrm{~K}$ was measured at 686,695 , and 730 $\mathrm{nm}$ for $\mathrm{pH}$ values of $6.2,7.7$, and 8.8. Values of $\tau$ at $\mathrm{pH} 7$ were reported in Ref 16. The addition of $\mathrm{Na}^{+}$to salt-depleted thylakoids causes decreases in $\tau\left(F_{686, \mathrm{~m}}\right)$ and $\tau\left(F_{695, \mathrm{~m}}\right)$ : from 0.35 to $0.24 \mathrm{~ns}$ for $\tau\left(F_{686, \mathrm{~m}}\right)$ and from 0.57 to $0.46 \mathrm{~ns}$ for $\tau\left(F_{695, \mathrm{~m}}\right)$ at $\mathrm{pH} 7.7$ and 8.8 ; at $\mathrm{pH} 6.2$, there is no cation-induced change $\left(\tau\left(F_{685, \mathrm{~m}}\right) \simeq 0.53 \mathrm{~ns} ; \tau\left(F_{695, \mathrm{~m}}\right) \simeq 0.7 \mathrm{~ns}\right)$. Subsequent addition of $\mathrm{Mg}^{2+}$ causes increases in $\tau\left(F_{685, \mathrm{~m}}\right)$ from 0.51 to $0.83 \mathrm{~ns}$ (at $\left.\mathrm{pH} 6.2\right)$, from 0.25 to $0.54 \mathrm{~ns}$ (at $\mathrm{pH} 7.7$ ), and from 0.23 to $0.43 \mathrm{~ns}$ (at $\mathrm{pH} 8.8$ ). The increases in

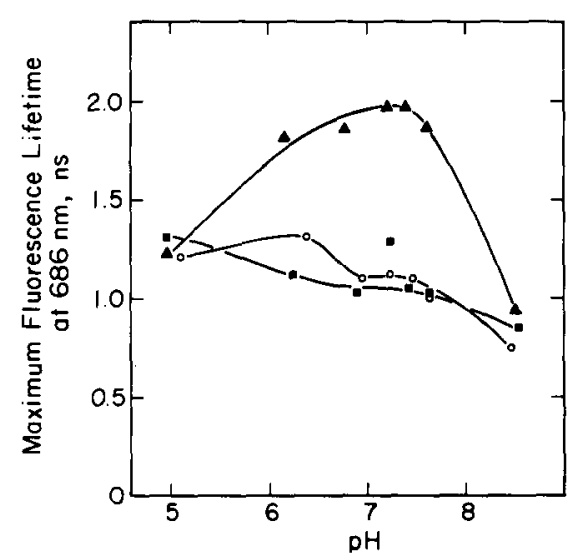

Fig. 4. pH dependence of the lifetime of the maximum fluorescence at $686 \mathrm{~nm}, \tau\left(F_{686, m}\right)$, for the saltdepleted $(\circ \longrightarrow), \mathrm{Na}^{+}(\square-\longrightarrow)$, and $\mathrm{Na}^{+}+\mathrm{Mg}^{2+}(\bullet-\longrightarrow)$ samples. Fluorescence excitation was at $632.8 \mathrm{~nm}$ and emission was detected through an interference filter at $686 \mathrm{~nm}$ (half-bandwidth, $6.8 \mathrm{~nm}$ ). Lifetimes were measured as described in Ref. [11]. 
TABLE II

CATION EFFECTS ON THE POLARIZATION OF CHLOROPHYLL $a$ FLUORESCENCE FOR TWO pH VALUES

Samples were $3 \mathrm{ml}$ thylakoid suspensions in $100 \mathrm{mM}$ sucrose $+2 \mathrm{mM}$ Tris-HNO 3, [Chl] $=5 \mu \mathrm{g} / \mathrm{ml}$, and [DCMU] $=3.3 \mu \mathrm{M}$. NaCl and $\mathrm{MgCl}_{2}$ were added to the final concentration of $5 \mathrm{mM}$. Excitation was at $630 \pm 2.5 \mathrm{~nm}$ and fluorescence was measured through a long-pass filter (Schott RG 665) and a $686 \mathrm{~nm}$ interference filter (half-bandwidth $=6.8 \mathrm{~nm}$ ). The temperature was $24^{\circ} \mathrm{C}$.

\begin{tabular}{lll}
\hline Sample & pH & Degree of polarization (\%)* \\
\hline Salt-depleted & 6.6 & $2.8 \pm 0.1$ \\
$\mathrm{Na}^{+}$ & 6.6 & $3.1 \pm 0.1$ \\
$\mathrm{Na}^{+}+\mathrm{Mg}^{2+}$ & 6.6 & $2.8 \pm 0.1$ \\
Salt-depleted & 9.0 & $2.5 \pm 0.1$ \\
$\mathrm{Na}^{+}$ & 9.0 & $2.6 \pm 0.1$ \\
$\mathrm{Na}^{+}+\mathrm{Mg}^{2+}$ & 9.0 & $2.3 \pm 0.1$ \\
\hline
\end{tabular}

* The degree of polarization $(\%)$ was calculated as $\left[\left(F_{\mathrm{V}}-F_{\mathrm{h}}\right) /\left(F_{\mathrm{v}}+F_{\mathrm{h}}\right)\right] \times 100$, where $F_{\mathrm{v}}$ and $F_{\mathrm{h}}$ are the intensities of vertically and horizontally polarized components of the fluorescence, when the actinic illumination is vertically polarized. Instrumental corrections were made as described by wong et al, [10].

$\tau\left(F_{695, \mathrm{~m}}\right)$ are from 0.7 to $1.1 \mathrm{~ns}$ at $\mathrm{pH} 6.2$, from 0.45 to $0.85 \mathrm{~ns}$ at $\mathrm{pH} 7.7$, and from 0.48 to $0.81 \mathrm{~ns}$ at $\mathrm{pH} 8.8$. The changes in $\tau\left(F_{730, \mathrm{~m}}\right)$ are small $(\leqslant 15 \%)$. $\tau\left(F_{730, \mathrm{~m}}\right)$, at various $\mathrm{pH}$ values, are $\sim 2.4 \mathrm{~ns}(\mathrm{pH} 6.2), \sim 2.1 \mathrm{~ns}(\mathrm{pH} 7.7)$ and $\sim 1.8 \mathrm{~ns}(\mathrm{pH} 8.8)$; there is a general decrease in $\tau$ at all wavelengths with increasing $\mathrm{pH}$.

Emission spectra. The cation effects on the emission spectra at $77 \mathrm{~K}$, normalized to their relative $\tau$ at $686 \mathrm{~nm}$, are shown in Fig. 5. The typical threeband spectrum with maxima at 685 (PS II), 693-696 (PS II), and $735 \mathrm{~nm}$ (PS I) is obtained for all values of $\mathrm{pH}$ and the three cationic conditions. At $\mathrm{pH}$ 6.3,

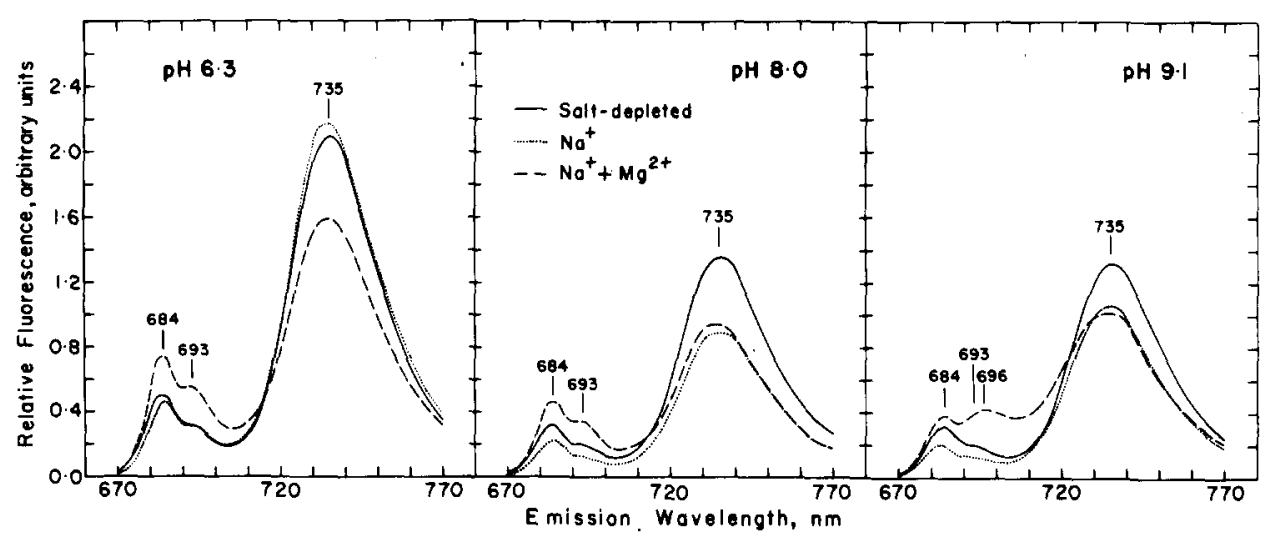

Fig. 5. Fluorescence emission spectra measured at $77 \mathrm{~K}$ for the salt-depleted, $\mathrm{Na}^{+}$, and $\mathrm{Na}^{+}+\mathrm{Mg}^{2+}$ samples for three $\mathrm{pH}$ values. All spectra were normalized to their respective lifetime values at $684 \mathrm{~nm}$. Excitation was at $636 \mathrm{~nm}$ (half-bandwidth, $8 \mathrm{~nm}$ ), and fluorescence was detected through a Schott RG 665 filter and a grating monochromator (band-pass, $2 \mathrm{~nm}$ ). All spectra were corrected for transmission characteristics of filter and monochromator, photomultiplier sensitivity, and stray light. [Chl] $=10 \mu \mathrm{g} / \mathrm{ml}$; $\left[\mathrm{Na}^{+}\right]=\left[\mathrm{Mg}^{2+}\right]=\sim 10 \mathrm{mM}$. Other details were as given in the text. 
$\sim 10 \mathrm{mM} \mathrm{Na}^{+}$causes a slight decrease in $F_{687}$ and a slight increase in $F_{735}$ (see Ref. 17); divalent cations, on the other hand, cause a large increase in $F_{684}$ and $F_{693}$ and a large decrease in $F_{735}$ (see Ref. 3). At pH 8.0 and 9.1 , however, $\mathrm{Na}^{+}$ causes a large decrease in the (relative) increase in the fluorescence at 684 and $693-696 \mathrm{~nm}$, but no change at $735 \mathrm{~nm}$.

Transients. The fluorescence transients at $77 \mathrm{~K}$ have been used for evaluating the energy distribution and redistribution in the two photosystems at $\mathrm{pH} 7.8$ (cf. Ref. 18). We present measurements of $F_{\mathrm{o}}$ and $F_{\mathrm{m}}$ at 690 and $730 \mathrm{~nm}$ at $\mathrm{pH} 6.2$ and 8.8 (Table III). Here, the fluorescence at $690 \mathrm{~nm}$, mainly from PS II, for the different samples was normalized by taking $\tau\left(F_{690}\right)=\left[\tau\left(F_{686}\right)+\tau\left(F_{695}\right)\right] /$ 2 . Even the emission at $730 \mathrm{~nm}$, mainly from PS I, has a 'variable' fluorescence $F_{\mathrm{v}}\left(10-20 \%\right.$ of $F_{\mathrm{m}}$ at $\left.730 \mathrm{~nm}\right)$; it is suggested [18] that this component results from energy transfer from PS II to PS I.

$F_{\mathrm{v}} / F_{\mathrm{m}}$ at $690 \mathrm{~nm}$ (Table III), by an earlier analysis [19], is the product of the efficiency of excitation transfer from the antenna to the reaction center of PS II and the efficiency of back-transfer from the closed center, and is taken as an index of the extent of excitation cycling between the antenna and the reaction center. At both acid and basic values of $\mathrm{pH}$, the addition of $10 \mathrm{mM} \mathrm{Na}{ }^{+}$to salt-depleted thylakoids lowers $F_{\mathrm{v}} / F_{\mathrm{m}}$ (at $690 \mathrm{~nm}$ ), and, thus, the energy cycling. However, the subsequent addition of $10 \mathrm{mM} \mathrm{Mg}^{2+}$, while increasing $F_{\mathrm{v}} / F_{\mathrm{m}}$ at acid $\mathrm{pH}$, causes a further decrease in the ratio at basic $\mathrm{pH}$.

Excitation distribution and redistribution in Photosystem II. From the above data on $\tau$ and transients, estimates (Table IV) of the energy distribution and redistribution parameters in PS II were made by a method similar to that described in Refs. 18 and 19, but to which measurements of $\tau$ were incorporated for estimating the fractional absorption by each photosystem in individual thylakoid samples (cf. Ref. 20, and footnote in Table IV). Our findings are: (1) at $\mathrm{pH} 6.2,10 \mathrm{mM} \mathrm{Na}^{+}$induces a smaller decrease in $\beta$ (the fraction of total absorbed quanta initially partitioned to PS II) than the increase induced

\section{TABLE III}

CATION EFFECTS ON THE INITIAL AND THE MAXIMUM FLUORESCENCE AT $77 \mathrm{~K}$ AT 690 AND $730 \mathrm{~nm}$ FOR TWO $\mathrm{pH}$ VALUES

Thylakoid suspensions ( $0.5 \mathrm{ml}$ each) in $100 \mathrm{mM}$ sucrose $+2 \mathrm{mM}$ Tris-HNO 3 were adsorbed on two layers of cheese-cloth $(0.3 \mathrm{~mm}$ thickness) and frozen at $77 \mathrm{~K}$. Excitation was through a $636 \mathrm{~nm}$ interference filter (half-bandwidth $=8 \mathrm{~nm}$ ), and fluorescence was measured through a Corning CS 2-59 glass filter and a monochromator set at $690 \mathrm{~nm}$ (band-pass $=10 \mathrm{~nm}$ ). Chlorophyll concentration was $20 \mu \mathrm{g} / \mathrm{ml},[\mathrm{NaCl}]=$ $\left[\mathrm{MgCl}_{2}\right]=9.8 \mathrm{mM}$. For meaning of symbols, see the legend of Table I.

\begin{tabular}{|c|c|c|c|c|c|c|}
\hline \multirow[t]{3}{*}{ Sample } & \multirow[t]{3}{*}{$\mathbf{p H}$} & \multicolumn{3}{|c|}{$690 \mathrm{~nm}$} & \multicolumn{2}{|c|}{$730 \mathrm{~nm}$} \\
\hline & & \multirow[t]{2}{*}{$F_{0}$} & \multirow[t]{2}{*}{$F_{\mathrm{m}}$} & \multirow{2}{*}{$\frac{F_{\mathrm{v}}}{F_{\mathrm{m}}}$} & \multirow[t]{2}{*}{$F_{\mathrm{o}}$} & \multirow[t]{2}{*}{$F_{\mathrm{m}}$} \\
\hline & & & & & & \\
\hline Salt-depleted & 6.2 & 22.3 & 65.1 & 0.66 & 237.2 & 300.8 \\
\hline $\mathrm{Na}^{+}$ & 6.2 & 29.5 & 62.1 & 0.53 & 277.0 & 339.2 \\
\hline $\mathrm{Na}^{+}+\mathrm{Mg}^{2+}$ & 6.2 & 36.6 & 100.0 & 0.63 & 216.8 & 257.8 \\
\hline Salt-depleted & 8.8 & 19.9 & 47.7 & 0.58 & 232.6 & 265.9 \\
\hline $\mathrm{Na}^{+}$ & 8.8 & 24.0 & 36.4 & 0.34 & 204.9 & 225.0 \\
\hline $\mathrm{Na}^{+}+\mathrm{Mg}^{2+}$ & 8.8 & 47.7 & 63.6 & 0.25 & 174.4 & 186.3 \\
\hline
\end{tabular}


TABLE IV

ENERGY DISTRIBUTION AND REDISTRIBUTION PARAMETERS IN PHOTOSYSTEM II BASED ON $77 \mathrm{~K}$ FLUORESCENCE TRANSIENTS AND LIFETIMES FOR TWO pH VALUES

The fraction of total absorbed quanta initially partitioned to PS II $(\beta)$ and the efficiencies for de-excitation of excited chlorophyll in the antenna complex of PS II, namely, thermal dissipation ( $\psi \mathrm{D} 2)$, fluorescence $\left(\eta_{\mathrm{F} 2}\right)$, and energy transfer to PS I $\left(\psi_{\mathrm{T}(21)}\right)$ and to reaction center II $\left(\psi_{\mathrm{T} 2}\right)$, were calculated for individual samples, using fluorescence lifetime and transients measured at $77 \mathrm{~K}$ and equations described in Refs. 19 and 20 . [Cations] $\simeq 10 \mathrm{mM}$.

\begin{tabular}{llllll}
\hline Sample & $\mathrm{pH}$ & $\beta *$ & $\eta_{\mathrm{F} 2}$ & $\psi_{\mathrm{T}(21)}$ & $\psi_{\mathrm{D} 2}+\psi_{\mathrm{T} 2}$ \\
\hline Salt-depleted & 6.2 & 0.54 & 0.01 & 0.14 & 0.85 \\
$\mathrm{Na}^{+}$ & 6.2 & 0.52 & 0.02 & 0.24 & 0.74 \\
$\mathrm{Na}^{+}+\mathrm{Mg}^{2+}$ & 6.2 & 0.57 & 0.02 & 0.09 & 0.89 \\
$\mathrm{Salt}^{+}$ & 8.8 & 0.46 & 0.01 & 0.13 & 0.86 \\
$\mathrm{Na}^{+}$ & 8.8 & 0.51 & 0.02 & 0.23 & 0.75 \\
$\mathrm{Na}^{+}+\mathrm{Mg}^{2+}$ & 8.8 & 0.58 & 0.03 & 0.18 & 0.79
\end{tabular}

* $\beta$ was calculated as $1-\alpha$, where $\alpha$ is the fraction of total absorbed quanta initially partitioned to PS I. $\alpha$ was calculated according to the equation:

$$
\alpha=\frac{F_{730, \alpha}}{F_{730, \alpha}+F_{690, \mathrm{~m}} \cdot \frac{\tau\left(F_{730, \mathrm{~m}}\right)}{\tau\left(F_{690, \mathrm{~m}}\right)}},
$$

where $F_{730, \alpha}=F_{730,0}-\left(F_{690,0} / \mathrm{F690,v}\right) \cdot F_{730, v} ; F_{730,0}=$ 'constant' fluorescence at $730 \mathrm{~nm}$; $F_{690,0}, F_{690, v}$, and $F_{690, \mathrm{~m}}=$ 'constant', 'variable', and maximum fluorescence at $690 \mathrm{~nm} ; \tau\left(F_{730, \mathrm{~m}}\right)$ and $\tau\left(F_{690, \mathrm{~m}}\right)=$ lifetimes of $F_{\mathrm{m}}$ at 730 and $690 \mathrm{~nm} . \tau\left(F_{690, \mathrm{~m}}\right)$ was taken as $\left[\tau\left(F_{686, \mathrm{~m}}\right)+\right.$ $\tau\left(F_{695)}\right) / 2$.

by the subsequent addition of $10 \mathrm{mM} \mathrm{Mg}{ }^{2+}$; at $\mathrm{pH} 8.8$, both $\mathrm{Na}^{+}$and $\mathrm{Mg}^{2+}$ induce approximately the same $(\sim 10 \%)$ increase in $\beta$. (2) The $\mathrm{Mg}^{2+}$-induced decrease in the efficiency of energy redistribution from PS II to PS I, $\psi_{\mathrm{T}(21)}$, is $\sim 60 \%$ at $\mathrm{pH} 6.2$ and $\sim 22 \%$ at $\mathrm{pH} 8.8$. The sum of efficiencies of nonradiative processes other than energy transfer from PS II to PS I, $\psi_{\mathrm{D} 2}+\psi_{\mathrm{T} 2}$, shows a slight decrease with $\mathrm{Na}^{+}$addition at both $\mathrm{pH}$ values; subsequent addition of $\mathrm{Mg}^{2+}$ causes some increase at $\mathrm{pH} 6.2$, but no significant change at $\mathrm{pH} 8.8$.

\section{$\mathrm{Mg}^{2+}$ effects on electron transport}

\section{Electron transport in light-limiting conditions}

The effects of cations at low light intensities, presented below, are related to the excitation energy distribution and redistribution discussed above; these results confirm the concept that cations indeed regulate excitation distribution between the two photosystems, and extend the validity of this concept to a wider range of $\mathrm{pH}$ values.

$P S$ II partial reaction: $\mathrm{H}_{2} \mathrm{O} \rightarrow D C I P$. It was necessary to confirm for our samples the reported cation effects before proceeding with new measurements on $\mathrm{pH}$ effects. The use of low actinic light intensities (linear portion of the light curves), high concentration of DCIP, and slow steady-state measurements, assured us that this was a PS II reaction (cf. Ref. 21). The $\mathrm{Mg}^{2+}$ enhancement of the rate of the $\mathrm{H}_{2} \mathrm{O} \rightarrow$ DCIP Hill reaction confirmed, in our preparations, most previous reports of the effects of this cation. However, additional results in Table V extend the validity of this effect to $\mathrm{pH} 5.4$ and 8.2. In particular, we 
$\mathrm{Mg}^{2+}$ EFFECT ON THE $\mathrm{H}_{2} \mathrm{O} \rightarrow$ DCIP ELECTRON TRANSPORT RATE UNDER LIGHT-LIMITING CONDITIONS FOR THREE PH VALUES

$[\mathrm{Chl}]=10 \mu \mathrm{g} / \mathrm{ml} ;[\mathrm{DCIP}]=30 \mu \mathrm{M} ;\left[\mathrm{NH}_{4} \mathrm{Cl}\right]=9.8 \mathrm{mM} ;\left[\mathrm{Mg}^{2+}\right]=9.8 \mathrm{mM} ;$ full actinic intensity at 635 $\mathrm{nm}=10 \mathrm{~mW} / \mathrm{cm}^{2}$. DCIP reduction was measured as a bleaching at $597 \mathrm{~nm}$, using a $3 \mathrm{ml}$ suspension of thylakoids in a $1-\mathrm{cm}$ path-length cuvette. Other details as given in the text.

\begin{tabular}{|c|c|c|c|}
\hline \multirow[t]{2}{*}{ pH } & \multirow{2}{*}{$\begin{array}{l}\text { Actinic } \\
\text { intensity } \\
(\%)\end{array}$} & \multicolumn{2}{|c|}{ Electron transport rates ( $\mu$ equiv./mg Chl/h) } \\
\hline & & $-\mathrm{Mg}^{2+}$ & $+\mathrm{Mg}^{2+}$ \\
\hline 5.4 & 75 & 5.1 & 7.2 \\
\hline \multirow[t]{2}{*}{7.3} & 12 & 5.4 & 9.0 \\
\hline & 75 & 37.1 & 47.7 \\
\hline 8.2 & 12 & 2.3 & 4.0 \\
\hline
\end{tabular}

note the 2-fold enhancement at $\mathrm{pH} 8.2$ (at $12 \%$ intensity) of PS II reaction upon the addition of $\mathrm{Mg}^{2+}$; this suggests that in the absence of $\mathrm{Mg}^{2+}$, there must be a massive spill over of energy from PS II to PS I.

PSI partial reaction: DCIPH $\rightarrow$ methylviologen. The intent of these experiments was to test whether or not $\mathrm{Mg}^{2+}$ causes an equivalent reduction in the electron transport rate in PS I at pH above 7.5 [4], when NADP ${ }^{+}$is replaced by methylviologen as electron acceptor. The results in Fig. 6 show that, at both pH 7.0 and $8.2, \mathrm{Mg}^{2+}$ causes only a decrease in the PS I electron transport rate, but the \% decrease, at low light intensities, is much smaller than the \% increase in PS II reaction. More experiments, under identical conditions for PS II and PS I reactions, are required to obtain quantitative information. Hoch (Hoch, G., personal communication) has pointed out that our experiments should be repeated in the absence of ammonium chloride before firm conclusions are made. In addition, he suggests that in the absence of $\mathrm{Mg}^{2+}$, the energy 'spilled over' from PS II to PS I may be delivered to those PS I units that are not engaged in the non-cyclic electron flow!

\section{Electron transport in light-saturating conditions}

We emphasize here that the effects of cations on PS I and PS II reactions in saturating light, reported below, are not related to the excitation energy distribution and redistribution phenomenon, and are most probably due to effects on some dark reaction(s), including effects on the affinity of electron carriers to the membrane.

PS II partial reactions. $\mathrm{H}_{2} \mathrm{O} \rightarrow \mathrm{Fe}\left(\mathrm{CN}_{6}\right)^{3-}$. At $\mathrm{pH}<7.8, \mathrm{Mg}^{2+}$ enhances the electron transport rate, but, at $\mathrm{pH}>7.8, \mathrm{Mg}^{2+}$ inhibits this rate; the maximum stimulation is $\sim 30 \%$ at pH 7.0 (Fig. 7). (2) $\mathrm{H}_{2} \mathrm{O} \rightarrow$ DCIP. Only a slight $\mathrm{Mg}^{2+}$. induced decrease is observed in this Hill reaction in the presence of DBMIB under light-saturating conditions (Table VI), the effect declining with increasing $\mathrm{pH}: \sim 10 \%$ at $\mathrm{pH} 6.4$ and $\sim 5 \%$ at $\mathrm{pH} 8.3$.

PS I partial reactions. $D A D_{\text {red }} \rightarrow$ methylviologen. The saturation rates for electron transport from $\mathrm{DAD} /$ ascorbate to methylviologen are unaffected by $\mathrm{Mg}^{2+}$ at acid and neutral values of $\mathrm{pH}$; at $\mathrm{pH} 8.0, \mathrm{Mg}^{2+}$ induces a slight increase, 

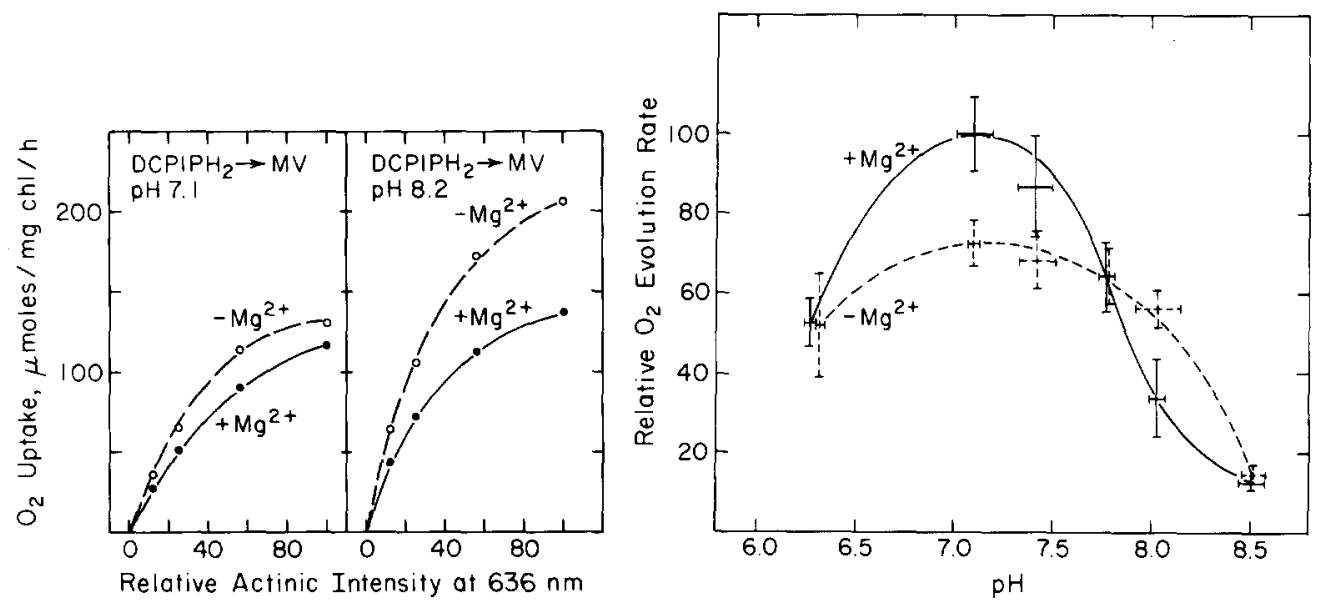

Fig. 6. Rates of Photosystem I partial electron transport under light-limiting conditions. Actinic light was at $636 \mathrm{~nm}$ (half-bandwidth, $8 \mathrm{~nm}$ ) at a maximum intensity of $22 \mathrm{~mW} / \mathrm{cm}^{2}$. [ Chl] $\simeq 25 \mu \mathrm{g} / \mathrm{ml} ;\left[\mathrm{NH}_{4} \mathrm{Cl}\right]=$ $9.5 \mathrm{mM} ;[D C M U]=4.8 \mu \mathrm{M} ;[D C I P]=60 \mu \mathrm{M} ;$ [sodium ascorbate $]=1.9 \mathrm{mM} ;[$ methylviologen, $\mathrm{MV}]=$ $95 \mu \mathrm{M} ;\left[\mathrm{MgCl}_{2}\right]$ (when added) $=9.5 \mathrm{mM}$; temperature $=25 \pm 1^{\circ} \mathrm{C}$. In this system, $1 \mathrm{~mol}$ of $\mathrm{O}_{2}$ uptake is equivalent to 1 electron transferred.

Fig. 7. Rates of Photosystem II partial electron transport $\left(\mathrm{H}_{2} \mathrm{O}\right.$ to ferricyanide) under light saturation conditions. A relative rate of 100 denotes $144 \mu \mathrm{mol} \mathrm{O} \mathrm{O}_{2}$ evolved $/ \mathrm{mg} \mathrm{Chl} / \mathrm{h}$. The results were the average of the absolute rates measured for three different thylakoid preparations; the error bars denote one standard deviation. [Chl] $=25 \mu \mathrm{g} / \mathrm{ml} ;\left[\mathrm{NH}_{4} \mathrm{Cl}\right]=5 \mu \mathrm{g} / \mathrm{ml} ;\left[\mathrm{K}_{3} \mathrm{Fe}\left(\mathrm{CN}_{6}\right)\right]=0.75 \mathrm{mM} ;$ when added, $\left[\mathrm{MgCl}_{2}\right]=9.8$ $\mathrm{mM}$. Actinic illumination for all measurements was from a tungsten lamp passed through a water filter and a Corning 3-73 filter; the irradiance at the sample was $175 \mathrm{~mW} / \mathrm{cm}^{2}$. The temperature was regulated at $25 \pm 1^{\circ} \mathrm{C}$.

\section{TABLE VI}

$\mathrm{Mg}^{2+}$ EFFECTS ON THE SATURATION RATES OF ELECTRON TRANSPORT IN PS I AND PS II PARTIAL REACTIONS AT VARIOUS pH VALUES

PS II partial reactions: $[\mathrm{Chl}] \simeq 15 \mathrm{~g} / \mathrm{ml} ;\left[\mathrm{NH}_{4} \mathrm{Cl}\right]=9.6 \mathrm{mM} ;[\mathrm{DBMIB}]=0.5 \mu \mathrm{M} ;[\mathrm{DCIP}]=60 \mu \mathrm{M}$; and $\left[\mathrm{MgCl}_{2}\right]$ (when added) $=9.6 \mathrm{mM}$. PS I partial reactions: [Chl] $\simeq 25 \mu \mathrm{g} / \mathrm{ml} ;\left[\mathrm{NH}_{4} \mathrm{Cl}\right]=9.5 \mathrm{mM} ;$ [DCIP] $=$ $60 \mu \mathrm{M} ;$ [sodium ascorbate] $=1.9 \mathrm{mM} ;[\mathrm{DAD}]=0.5 \mathrm{mM} ;[\mathrm{MV}] *=95 \mu \mathrm{M} ;[\mathrm{DCMU}]=4.8 \mu \mathrm{M} ;$ and $\left[\mathrm{MgCl}_{2}\right]=9.5 \mathrm{mM}$. Illumination conditions were as given in the legend of Fig. 7 , and other details as given in the text. The temperature was regulated at $25 \pm 1^{\circ} \mathrm{C}$.

\begin{tabular}{|c|c|c|c|}
\hline \multirow[t]{2}{*}{ Reaction } & \multirow[t]{2}{*}{$\mathbf{p H}$} & \multicolumn{2}{|c|}{ Electron transport rates ( $\mu$ equiv. $/ \mathrm{mg} \mathrm{Chl} / \mathrm{h}$} \\
\hline & & $-\mathrm{Mg}^{2+}$ & $+\mathrm{Mg}^{2+}$ \\
\hline \multicolumn{4}{|l|}{ PS II } \\
\hline \multirow[t]{2}{*}{$\mathrm{H}_{2} \mathrm{O} \rightarrow$ DCPIP (+ DBMIB) } & 6.4 & 248 & 216 \\
\hline & 8.3 & 257 & 243 \\
\hline \multicolumn{4}{|l|}{ PS I } \\
\hline \multirow[t]{3}{*}{$\mathrm{DAD}_{\text {red }} \rightarrow \mathrm{MV} *$} & 6.3 & 205 & 208 \\
\hline & 7.3 & 202 & 206 \\
\hline & 8.0 & 223 & 309 \\
\hline \multirow[t]{2}{*}{$\mathrm{DCPIPH}_{2} \rightarrow \mathrm{MV}$} & 7.1 & 316 & 333 \\
\hline & 8.2 & 630 & 569 \\
\hline
\end{tabular}

* MV in this table stands for methylviologen. 
if any, in the electron transport rate at $\mathrm{pH} 7.1$, but gives a $10 \%$ decrease at $\mathrm{pH}$ 8.2 (Table VI).

\section{Discussion}

The maximum cation effects over the $\mathrm{pH}$ range 6 to 9 are observed (Fig. 1) at concentrations of $\sim 10 \mathrm{mM}$, and, unless otherwise stated, it will be understood throughout this section that cations are added to this concentration.

The first point of interest was to determine the $\mathrm{pH}$ range over which the earlier conclusions regarding the role of $\mathrm{Na}^{+}$and $\mathrm{Mg}^{2+}$ in the initial distribution and redistribution of electronic excitation in and between the two photosystems are valid. An earlier conclusion for spinach $[15,17]$ appears to hold in pea thylakoids only for $\mathrm{pH}>6.1$ (also see Ref. 22). The $\mathrm{Mg}^{2+}$-induced enhancement of fluorescence yield, however, holds from $\mathrm{pH}$ of $\sim 5$ to 9 (Figs. 3 and 4 ), with the maximum effect around $\mathrm{pH}$ 7.5. The fraction of total absorbed quanta initially distributed (or partitioned) to PS II, $\beta$, is decreased by $\mathrm{Na}^{+}$at $\mathrm{pH}>6.2$ and increased by $\mathrm{Mg}^{2+}$ over the entire $\mathrm{pH}$ range 6 to $9 . \mathrm{Na}^{+}$-induces an increase in the efficiency of excitation transfer from PS II to PS I, $\psi_{\mathrm{T}(21)}$, and $\mathrm{Mg}^{2+}$ induces a decrease in the efficiency of this transfer over the $\mathrm{pH}$ range 6.2 to 8.8. This conclusion derived from $77 \mathrm{~K}$ fluorescence (Table IV) is supported at room temperature by measurements on (a) the degree of polarization of fluorescence at $686 \mathrm{~nm}$ (mainly PS II) and at $712 \mathrm{~nm}$ (mainly PS I); (b) fluorescence lifetimes (Fig. 4); and (c) rates of electron flow at low light intensities (Table $\mathrm{V}$ and Fig. 6). $\mathrm{Mg}^{2+}$ causes a larger relative increase in PS II reaction than the relative decrease in PS I reaction; however, it should be noted that the inadequacy of electron transport data is that they do not provide any information regarding the fractional contributions of initial distribution of absorbed quanta and subsequent redistribution in the overall change.

The second point of interest was to examine the implications of the earlier report [4] that the light-limited rate of electron transport from $\mathrm{DCIPH}_{2}$ to $\mathrm{NADP}^{+}$is stimulated or inhibited by $\mathrm{Mg}^{2+}$ depending upon whether the bulk $\mathrm{pH}$ is below or above 7.5. EPR measurements [23] of steady-state P-700 oxidation at low light intensities support the $\mathrm{Mg}^{2+}$ inhibition of electron transport through PS I from $\mathrm{DCIPH}_{2}$ to methylviologen at the $\mathrm{pH}$ used. We find here that $\mathrm{Mg}^{2+}$ induces only an $\sim 35 \%$ decrease in the light-limited electron transport rates from $\mathrm{DCIPH}_{2}$ to methylviologen in diuron treated thylakoids at $\mathrm{pH} 7.1$ and 8.2 (Fig. 6). Thus, the conclusions regarding the stimulation of PS I reaction at $\mathrm{pH}<7.5$ should be considered with great caution.

The third point of concern in this investigation was the $\mathrm{pH}$ sensitivity of the cation effects. Since the thylakoid surface is negatively charged [24], protons should be expected to compete with cations if the effects of the latter are mainly electrostatic (cf. Ref. 5). Mohanty et al. [25] showed that lowering the $\mathrm{pH}$ to 3.8 in oat thylakoids causes a decreased energy transfer from PS II to PS I just as $\mathrm{Mg}^{2+}$ does. Information accumulated in the present paper suggests the presence of two roles for $\mathrm{pH}$ in regulating the cation effects: (1) The increasing effectiveness of $\mathrm{Na}^{+}$with decreasing $\mathrm{pH}$ (Fig. 1A) is taken to indicate the similarity of the effect of the two monovalent cations. The lowering of the half-saturation concentration for the $\mathrm{Mg}^{2+}$ effect with increasing $\mathrm{pH}$ (Fig. 1B) is 
interpreted to indicate competition between $\mathrm{H}^{+}$and $\mathrm{Mg}^{2+}$. (2) The $\mathrm{pH}$ dependence of the electrophoretic mobility of thylakoids shows an almost constant response between $\mathrm{pH} 6$ and 10 [24]. Thus, the variety of $\mathrm{pH}$ dependences found in this study - for instance, the strong dependence on $\mathrm{pH}$ of the divalent cation effects on steady-state fluorescence yield (Figs. 3 and 4 ) - requires further study and explanation.

Finally, in Itoh's concept [26], the site of ferricyanide reduction in system II exists inside the membrane with negative surface charges hindering the access of ferricyanide by electrostatic repulsion; cations would screen these membrane charges and, thus, increase the rate of reduction of ferricyanide in saturating light. This pciture readily accounts for the $\mathrm{Mg}^{2+}$-induced stimulation of ferricyanide reduction at $\mathrm{pH}<7.8$ (Fig. 7). It also accounts for the absence of the stimulatory effect on the reduction of the neutral molecule like DCIP. It appears, however, that other factors limiting ferricyanide accessibility - e.g., membrane stacking - must be considered, at $\mathrm{pH}<7.8$.

\section{References}

1 Barber, J. (1976) in The Intact Chloroplast (Barber, J., ed.), pp. 89-134, Elsevier, Amsterdam

2 Williams, W.P. (1977) in Primary Processes of Photosynthesis (Barber, J., ed.), pp. 99-147, Elsevier, Amsterdam

3 Murata, N. (1969) Biochim. Biochim. Biophys. Acta 189, 171-181

4 Rurainski, H.J. and Mader, G. (1978) Z. Naturforsch. 33c, 664-666

5 Barber, J., Mills, J. and Love, A. (1977) FEBS Lett. 75, 174-181

6 Wong, D., Govindjee and Jursinic, P. (1978) Photochem. Photobiol. 28, 963-974

7 Shimony, C., Spencer, J. and Govindjee (1967) Photosynthetica 1, 113-125

8 Munday, J.C., Jr. and Govindjee (1969) Biophys. J. 9, 1-21

9 Wong, D. and Govindjee (1979) Febs Lett. 97, 373-379

10 Wong, D., Vacek, K., Merkelo, H. and Govindjee (1978) Z. Naturforsch. 33C, 863-869

11 Merkelo, H., Hartman, S.R., Mar, T., Singhal, G.S. and Govindjee (1969) Science 164, $301-302$

12 Armstrong, J.M. (1964) Biochim. Biophys. Acta 86, 194-197

13 Arnon, D.I. (1949) Plant Physiol. 24, 1-15

14 Mills, J.D. and Barber, J. (1978) Biophys. J. 21, 257-272

15 Wydrzynski, T., Gross, E.L. and Govindjee (1976) Biochim. Biophys. Acta 376, 151-161

16 Wong, D., Merkelo, H. and Govindjee (1979) FEBS Lett. 104, 223-226

17 Gross, E.L. and Hess, S.C. (1973) Arch. Biochem. Biophys, 159, 832-836

18 Butler, W.L. and Kitajima, M. (1975) Biochim. Biophys. Acta 396, 72-85

19 Butler, W.L. and Kitajima, M. (1975) in Proceedings of the Third International Congress on Photosynthesis (Avron, M., ed.), Vol. 1, pp. 13-24, Elsevier, Amsterdam

20 Wong, D. (1979) Ph.D. Thesis, University of Illinois, Urbana-Champaign, IL

21 Fork, D.C. and Amesz, J. (1969) Annu. Rev, Plant Physiol. 20, 205-238

22 Vandermeulen, D. and Govindjee (1974) Biochim. Biophys. Acta 368, 61-70

23 Tikhonov, A.N., Ruuge, E.K. and Subchinski, V.K. (1977) Biofizika (Russ.) 22, 833-839

24 Nakatani, H.Y., Barber, J. and Forrester, J.A. (1978) Biochim. Biophys. Acta 504, 215-225

25 Mohanty, P., Braun, B.Z. and Govindjee (1972) Biochim. Biophys. Acta $292,459-472$

26 Itoh, S. (1978) Plant Cell Physiol. 19, 149-166 